\title{
Amyloid (AL) in an octogenarian diagnosed by abdominal wall fat biopsy
}

\author{
W.J.W. Mallinson, O.J. Corrado and S.R. Milkins
}

Departments of Geriatric Medicine and Histopathology, The Royal Free Hospital, Pond Street, London, NW3, $U K$.

\begin{abstract}
Summary: Systemic amyloid (AL) was diagnosed by abdominal wall fat biopsy in an 81 year old woman presenting with severe postural hypotension. The advantages of this little-used diagnostic method are discussed.
\end{abstract}

\section{Introduction}

Primary systemic amyloid is not commonly diagnosed in old people. ${ }^{1}$ The following case study illustrates several of the severe effects of this condition and discusses a means of making the diagnosis which is sensitive and free of complication, but which is not well-known and is thus underused.

\section{Case report}

An 81 year old woman came to hospital after 3 months' nausea, anorexia, weight loss, thirst, lethargy and postural dizziness. She was taking no medication. She had marked postural hypotension, blood pressure being $150 / 70 \mathrm{mmHg}$ lying and $80 / 60 \mathrm{mmHg}$ when standing. Liver and spleen were not palpable and there were no signs of peripheral neuropathy.

The results of investigations were: haemoglobin $11.9 \mathrm{~g} / \mathrm{dl}$, erythrocyte sedimentation rate $48 \mathrm{~mm} / \mathrm{hour}$, plasma urea $29.9 \mathrm{mmol} / 1$, sodium $129 \mathrm{mmol} / 1$, albumin $36 \mathrm{~g} / \mathrm{dl}$, total serum protein $66 \mathrm{~g} / \mathrm{dl}$, creatinine $0.28 \mathrm{mmol} / \mathrm{l}$, creatinine clearance $11 \mathrm{ml} / \mathrm{min}, 24$ hour urinary protein $3.8 \mathrm{~g}$. Renal tomography and ultrasound scanning showed kidneys of normal size with no sign of urinary tract obstruction.

When treated with supplementary oral sodium her dizziness improved and standing blood pressure rose to around $120 / 60 \mathrm{mmHg}$. The plasma urea fell to $10.4 \mathrm{mmol} / 1$ and creatinine to $0.11 \mathrm{mmol} / \mathrm{l}$ indicating a substantial extra-renal element to the uraemia. Addi-

Correspondence: W.J.W. Mallinson, M.B., M.R.C.P., St John's Hospital, St John's Hill, London SW11 1SP, UK.

Accepted: 10 September 1986 son's disease was excluded by a short Synacthen test.

The improvement was short-lived and postural symptoms soon returned. Attempts to correct this with elastic stockings and an abdominal binder were unsuccessful. She remained hypotensive even when fludrocortisone acetate and sodium supplements were given simultaneously, and subsequent albumin infusion gave only transient benefit. There was continuing proteinuria $(2-6 \mathrm{~g} / 24 \mathrm{~h})$ and gradually progressive renal impairment with the plasma creatinine rising to $0.48 \mathrm{mmol} / 1$. Serum electrophoresis showed a discrete band in the gamma region which, on immunofixation, was a monoclonal paraprotein of IgG lambda type measuring $5 \mathrm{~g} / 1$. Urine contained albumin, intact IgG lambda type immunoglobulin and free lambda light chains. Bone marrow aspirate showed a minor population of abnormal plasma cells but the total plasma cell proportion was not increased (7\%). Skeletal X-rays showed no myelomatous deposits.

The clinical and biochemical features of the patient's illness suggested the diagnosis of systemic amyloidosis. An abdominal wall fat biopsy was taken with a Tru-Cut needle (Travenol Laboratories Inc.) using local anaesthesia, this technique being thought preferable to the biopsy of a major organ in a patient who was so unwell. Amyloid material in the septa between fat cells was shown by Congo red staining.

The patient developed complete heart block and her condition deteriorated further in spite of cardiac pacing. She died after an illness of 8 months duration. The postural hypotension had never been satisfactorily controlled.

There was little gross abnormality on post-mortem examination. The spleen had a firm, waxy cut surface 
but was not enlarged. Microscopically there was a diffuse heavy deposition of amyloid related mainly to vessel walls, especially in the spleen, liver and kidneys. The myocardium was also infiltrated and amyloid seen in association with the atrio-ventricular node.

Although not increased in number, an abnormally high proportion of plasma cells in the bone marrow were seen to be lambda-chain-secreting by using the peroxidase-antiperoxidase method with polyclonal antisera (Dako Ltd) against light chains. Persistence of Congo red staining following pre-incubation of sections in potassium permanganate, ${ }^{2}$ gave further evidence that the amyloid was AL type.

\section{Discussion}

In a series of 229 patients with primary systemic amyloid (AL) from the Mayo Clinic ${ }^{1}$ only $5 \%$ of the 229 patients reported were in their eighth decade at the time of diagnosis, suggesting that it is not a common disease of the aged. Postural hypotension, which caused our patient's most disabling symptoms, is common in the elderly and has numerous causes. ${ }^{3}$ Although amyloid appears low on the diagnostic list it may pose intractable management problems as illustrated by the present case.

Confirmation of the diagnosis of amyloid is often difficult. Histological diagnosis is made by taking tissue from an organ which is clinically suspect, or by 'blind' biopsy; numerous 'blind' techniques have been used in the past. Percutaneous liver biopsy was

\section{References}

1. Kyle, R.A. \& Greipp, P.R. Amyloidosis (AL). Mayo Clin Proc 1983, 58: 665-683.

2. Van Rijswijk, M.H. \& Van Heudsen, C.W.G.J. The potassium permanganate method: a reliable method for differentiating amyloid AA from other forms of amyloid in routine laboratory practice. Am J Pathol 1979, 97: $43-58$.

3. Robbins, A.S. \& Rubenstein, L.Z. Postural hypotension in the elderly. J Am Geriatr Soc 1984, 32: 769-774.

4. Waldenstrom, $\mathrm{H}$. On the formation and disappearance of amyloid in man. Acta Chir Scand 1928, 63: 479-530. discussed by Waldenstrom as long ago as $1928 ;{ }^{4} \frac{2}{3}$ gingival biopsy was first reported by Selikoff $\& \stackrel{\mathbb{Q}}{\complement}$ Robitzek $^{5}$ with a positive yield of $70 \%$ from 26 cases $C$ and, later, rectal biopsy became the blind technique of $\vec{F}$ choice after its description by Gafni \& Sohar ${ }^{6}$. They $\stackrel{\oplus}{\rightarrow}$ confirmed the diagnosis with rectal biopsy in $85 \%$ of 30 cases but in the same series no patient $(0 / 9)$ had a positive gum biopsy.

More recently, Westermark \& Stenkvist ${ }^{7}$ described aspiration of subcutaneous fat from the anterior \& abdominal wall using a dry syringe and small needle. Multiple specimens could be obtained with minimal discomfort to the patient and immediate smears made onto microscope slides. After staining, amyloid material could be seen between fat cells. Using this method Libbey and co-workers ${ }^{8}$ obtained positive aspirates in $88 \%$ of 32 patients with systemic amyloid. We have modified this technique by using a needle biopsy, which has the additional advantage over aspiration that the larger sample(s) can readily be sectioned for multiple histochemical tests to improve their diagnostic utility.

Gafni \& Sohar ${ }^{6}$ stated criteria for 'an ideal routine biopsy technique for the diagnosis of amyloidosis' which were: a readily available involved organ, operative ease assuring an adequate specimen, absence of complications, and minimal discomfort to the patient. Abdominal wall fat biopsy is both safer an $\$$ simpler than rectal biopsy, satisfying Gafni \& Sohar criteria even better than the technique which the pioneered: it is certainly the method of first choice for the frail elderly patient such as we describe.

5. Selikoff, I.J. \& Robitzek, E.H. Gingival biopsy for the diagnosis of generalized amyloid. Am J Pathol 1947, 23: 1099-1111.

6. Gafni, J. \& Sohar, E. Rectal biopsy for the diagnosis of amyloidosis. Am J Med Sci 1960, 240: 332-336.

7. Westermark, P. \& Stenkvist, B. Diagnosis of secondary generalised amyloidosis by fine needle biopsy of the skin. Acta Med Scand 1971, 190: 453-454.

8. Libbey, C.A., Skinner, M. \& Cohen, A.S. Use of abdominal fat tissue aspirate in the diagnosis of systemic amyloidosis. Arch Int Med 1983, 143: 1549-1552. 